\title{
Navigator guided high-resolution single-shot black-blood (BB) TSE images using zoom and sensitivity encoding (sense) on a 32 channel RF system
}

\author{
Raja Muthupillai*1, Claudio Arena1, Amol Pednekar², \\ Ramkumar Krishnamurthy ${ }^{3}$, Scott Flamm ${ }^{4}$ and Benjamin Cheong ${ }^{1}$
}

\author{
Address: ${ }^{1}$ Department of Radiology, St.Luke's Episcopal Hospital and Texas Heart Institute, Houston, TX, USA, ${ }^{2}$ Philips Healthcare, Houston, TX, \\ USA, ${ }^{3}$ Rice University, Houston, TX, USA and ${ }^{4}$ Cleveland Clinic, Cleveland, $\mathrm{OH}$, USA \\ * Corresponding author
}

from I3th Annual SCMR Scientific Sessions

Phoenix, AZ, USA. 21-24 January 2010

Published: 21 January 2010

Journal of Cardiovascular Magnetic Resonance 2010, I2(Suppl I):O73 doi:10.1 I86/1532-429X-12-SI-O73

This abstract is available from: http://jcmr-online.com/content/I2/SI/O73

(C) 2010 Muthupillai et al; licensee BioMed Central Ltd.

\section{Introduction}

Although time consuming, double-inversion recovery prepared black-blood TSE imaging (BBI) techniques form the back bone of tissue characterization in cardiac MRI. While SSH-BBI is feasible, to-date, the spatial resolution of such SSH-BBI is intrinsically limited by the T2 decay induced blurring associated with the length of the readout duration. We hypothesize that by restricting the craniocaudal FOV to the heart using the ZOOM technique (which applies the 90 and 180 degree RF pulses orthogonal to each other), and by applying SENSE in the FH/RL direction with a 32 channel coil, it is feasible to obtain high-resolution single-shot BBI.

\section{Purpose}

The purpose of this work is to test the feasibility of this hypothesis in a clinical setting.

\section{Methods}

All imaging was done on $1.5 \mathrm{~T}$ Philips scanner with $32 \mathrm{RF}$ channels and VCG gating in 7 subjects $(6 \mathrm{M}$, age: $36 \pm 6$ yrs). The baseline SSH-BBI sequence (Base) had a TSE readout duration of $436 \mathrm{~ms}$. This readout duration was decreased to $260 \mathrm{~ms}$ by applying SENSE (factor $=2$ ), and further to $164 \mathrm{~ms}$ by restricting the FOV by $50 \%$ in the $\mathrm{FH} /$ RL direction using ZOOM, and by using SENSE in the FH/ RL direction (by a factor $=2$ ). The following acquisition parameters were kept constant across all three sequences: acquired voxel size $1.5 \times 2.0 \times 8.0 \mathrm{~mm} 3$; TR/EffTE: Infinity/80 ms; bandwidth per pixel: $500-520 \mathrm{~Hz}$. Only the half-scan parameter was adjusted to yield the same EffTE for all three sequences. A respiratory navigator positioned at the level of the diaphragm triggered each slice acquisition eliminating the need for breath-holding.

\section{Results}

Some representative images from the three imaging techniques are shown in Figure 1. Note the higher spatial resolution of the ZOOM+SENSE SSH technique compared to the conventional SSH approach. The shorter readout duration of ZOOM+SENSE further reduces blurring during readout, and images can be obtained during free breathing. While both SENSE and ZOOM reduce the number of phase encoding steps required to make an image without compromising spatial resolution, ZOOM provides some additional benefits compared to SENSE. Unlike SENSE, the incorporation of ZOOM does not entail a reduction in SNR, and it also facilitates the use of SENSE in the FH/RL direction (without foldover issues) that takes advantage of the multiple coil elements in the $\mathrm{FH} / \mathrm{RL}$ direction on a 32 channel coil.

\section{Conclusion}

High resolution SSH-BB TSE images can be obtained during free breathing with minimal blurring by a combination of SENSE and ZOOM imaging techniques. 


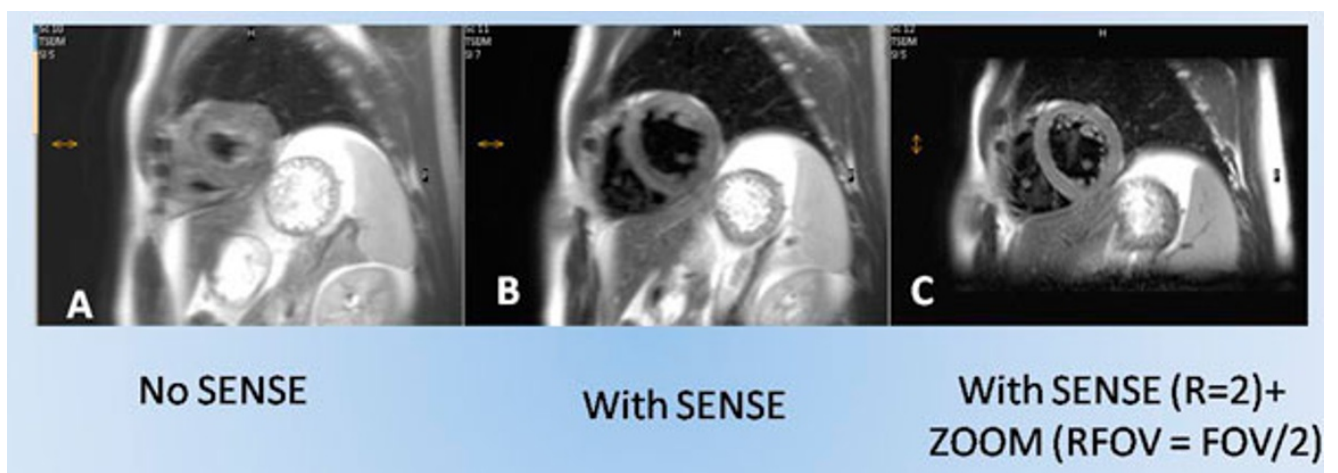

\section{Figure I}

A) Conventional SSH-BBI with TSE shot duration of $436 \mathbf{m s}$. Note the increased blurring and systolic acquisition due to the long readout; B) SSH-BBI with the applicatin of SENSE in AP direction dreduces the readout duration to 270 ms; C) SSH-BBI with SENCE (in the FH direction) and ZOOM reduces the readout duration further to 164 ms bringing a substantial improvement quality. The yellow arrows point the phase-encoding direction, and the acquired voxel size was $1.5 \times 2 \mathrm{~mm}$ for all three acquisitions.

Publish with Biomed Central and every scientist can read your work free of charge

"BioMed Central will be the most significant development for disseminating the results of biomedical research in our lifetime. "

Sir Paul Nurse, Cancer Research UK

Your research papers will be:

- available free of charge to the entire biomedical community

- peer reviewed and published immediately upon acceptance

- cited in PubMed and archived on PubMed Central

- yours - you keep the copyright
BioMedcentral 